\title{
Linking water quality with amphibian breeding and development: a case study comparing natural ponds and Sustainable Drainage Systems (SuDS) in East Kilbride, Scotland
}

\author{
R.J. Bird, E. Paterson, J.R. Downie \& B.K. Mable \\ Institute of Biodiversity, Animal Health and Comparative Medicine, University of Glasgow, Glasgow, Scotland G12 \\ 8QQ
}

E-mail: roger.downie@glasgow.ac.uk

\begin{abstract}
Amphibians have declined due to habitat loss and alteration. Sustainable Drainage Systems (SuDS) provide potential habitat for amphibians in urban landscapes. However, the contaminants they accumulate may cause increased pollutant exposure, and limited research has addressed whether differences in water quality between SuDS and natural ponds might restrict their use by amphibians. This study aimed to explore the effects of water quality on amphibian breeding and development in SuDS and natural ponds in East Kilbride, Scotland. A generalised linear modelling approach was employed to determine sources of variation in common frog (Rana temporaria) breeding and development in relation to pond size, $\mathrm{pH}$, electrical conductivity (EC), chlorophyll and heavy metal concentrations. Key findings included that EC indicative of salt pollution was higher in SuDS than natural ponds, amphibians bred in both site types, but frog spawn clump densities were lower in SuDS, and tadpole development rates were higher in SuDS sites but decreased when aluminium concentrations exceeded concentrations those of surface water standards. However, pond desiccation was a significant element in the 2018 study year. It was concluded that natural ponds and SuDS varied in water quality but were important in supporting amphibian populations. However, water quality might influence amphibian development more than breeding attempts; implications and management recommendations are highlighted based on these observations.
\end{abstract}

\section{INTRODUCTION}

The unprecedented rate at which amphibians are declining globally is attributed to numerous human induced pressures, of which the loss and alteration of habitat is especially detrimental (Stuart et al., 2005; Sodhi et al., 2008). The necessity of aquatic habitats for breeding in most amphibian species can render anthropogenic landscapes inhospitable, as water bodies can be sparse, inaccessible, and polluted. Furthermore, amphibians face a major ontogenetic shift following metamorphosis, which results in different habitat requirements during different life stages (Werner \& Gilliam, 1984). Continued alteration and loss of habitat presents novel challenges for species such as amphibians, which are a group that generally reacts negatively to urbanisation (Scheffers \& Paszkowski, 2012). Yet, some artificial landscapes can serve as viable habitat for wildlife species, and contemporary studies have documented amphibian populations utilising certain drainage systems such as stormwater ponds, detention/retention basins, and artificial wetlands (Birx-Raybuck et al., 2010; Brand \& Snodgrass, 2010; Hamer et al., 2012; Holzer, 2014; O’Brien, 2015). Additionally, Brand \& Snodgrass (2010) found that amphibians were predominantly found in artificial ponds and other human-made wetlands while surveying both suburban and forested watersheds, highlighting the importance of some urban water systems for amphibians; but also that specific habitat characteristics are strongly associated with successful amphibian breeding and occupancy.

A caveat to wildlife species using urban habitats is the potential for pollutant exposure. This is especially the case for amphibians due to their permeable skin (across which a high proportion of respiratory exchange occurs) and the physiological and habitat shifts they undergo through different life stages. The transition between aquatic and terrestrial habitats exposes most amphibian species to a variety of substances and environmental conditions, resulting in their characterisation as effective ecological indicator species (Carignan \& Villard, 2002). Thus, variation in water quality parameters is likely to influence their breeding and survival at different life stages. For example, salts applied to road systems can flow into adjacent waterways, leading to increased salinity levels and posing a risk for aquatic species such as pond breeding amphibians that dwell in these water bodies (Collins \& Russell, 2009; Karraker et al., 2016). Salt exposure can lead to increased mortality, increased severity and frequency of developmental deformities, heightened stress levels, reduced activity, and can deter pond occupancy in 
amphibians (Sanzo \& Hecnar, 2006; Collins \& Russell, 2009; Chambers, 2011; Hopkins et al., 2013; Hua \& Pierce, 2013). These negative impacts from salts can occur at different amphibian life stages and have long-lasting effects (Wu et al., 2012).

Nitrogen and phosphorus are common and essential for biological organisms, but can become pollutants when in high concentrations (Zhang et al., 2015; Garnache et al., 2016). Nitrogen and especially phosphorus in aquatic systems can lead to excess algal growth and eutrophication, which can create hypoxic conditions and adversely affect aquatic organisms and trophic interactions (Perkins \& Underwood, 2002; Guo, 2007). Furthermore, anthropogenic eutrophication can promote shifts in species composition and increase the prevalence of intermediate parasite hosts such as snails (Johnson \& Chase, 2004). Direct exposure to these chemicals can also harm amphibians, and nitrogen-based fertilisers such as ammonium nitrate have been shown to decrease the survival of wood frog tadpoles (Burgett \& Wright, 2007), and impair anti-predator behaviour by decreasing predator cue recognition in western spadefoot toad tadpoles (Pelobates cultripes) (Polo-Cavia et al., 2016). Eutrophication via nitrogen and phosphorus results from increased plant activity usually in the form of an algal bloom, and one way to indirectly measure nitrogen and phosphorus is through the presence of chlorophyll $a$. Heightened chlorophyll a concentrations can be indicative of negative effects on aquatic biota, and one study documented the prevalence of three amphibian species being inversely related to chlorophyll a concentrations (Jarosiewicz et al., 2014). Given the effects of nitrogen and phosphorus on amphibians and their prevalence in human dominated landscapes, additional research focusing on their impact at different magnitudes can inform conservation efforts to improve water quality in both urban and natural landscapes.

Metals are another category of naturally occurring substances that can become pollutants at unnatural concentrations. For example, larval amphibians exposed to chronic copper concentrations exhibited various negative effects, including hindering percent of animals reaching and time to metamorphosis, reduced survival, increased tail resorption time, and slower swimming speed (Chen et al., 2007). Exposure of Zhenhai brown frog (Rana zhenhaiensis) tadpoles to low copper concentrations induced a decrease in body mass, having negative implications for later life stages (Wei et al., 2015). Zhenhai brown frog tadpoles exposed to zinc had decreased mass and length as well as increased frequencies of abnormal erythrocytic nuclei. In addition to impairing growth and development, elevated zinc levels can compromise the ability of larval amphibians to escape predators by decreasing fright response (Lefcort et al., 1998). For gilled aquatic species such as newt larvae and early stage tadpoles, aluminium toxicity in water systems can hinder respiration through the upset of ion exchange and can also cause blockage through excess secretion of mucus (Gensemer \& Playle, 1999). Sensitivity to aluminium likely varies between amphibian species; for example, Pacific chorus frog (Pseudacris regilla) and long-toed salamander (Ambystoma macrodactylum) hatchlings and larvae exposed to aluminium treatments showed only sub-lethal effects (body size reduction, early hatching), but no reduction in survival (Bradford et al., 1994). The extent to which amphibians can tolerate metal pollution is still not fully understood and further research is needed.

With the increase of human population size and continued urbanisation, it has been realised that managing and improving urban wildlife areas foster many benefits. "Sustainable Drainage Systems" (SuDS) is a term used to describe systems of managing urban surface water with a "multi-benefit" approach of improving four main categories: water quality, water quantity, amenity (related to humans and aesthetics), and biodiversity (Woods Ballard et al., 2015). SuDS can take many forms, but examples that can directly benefit amphibians are artificial ponds, wetlands, swales (linear depressions, typically long and narrow), and retention basins (basins for holding water), all of which can be found in urban areas. SuDS are a relatively new scheme, which are increasingly being implemented in urban and suburban areas and their water management approach distinguishes them from previous drainage systems that focused solely on redirecting and caching water. How amphibians fare in SuDS is relatively unknown as few studies have addressed this topic. SuDS may harbour pollutants due to their proximity to developed areas and exposure to urban runoff, and a recent study found that fine sediments in SuDS networks were resuspended in the water column subsequent to multiple rainfall events (Allen et al., 2017a). These fine sediments can contain salts, metals, and other pollutants that are potentially harmful to aquatic wildlife and can hinder benefits to biodiversity. However, the contamination of sediments can vary greatly between SuDS types as well as specific sites; methods for removing sediment pollution accumulation have been suggested as the best way to ensure water quality and biodiversity benefits are maintained, while still allowing for large water quantities to be managed (Allen et al., 2017b). SuDS are still in their pilot stages and their benefits are not fully understood, but attempts to monetarily quantify their value have shown that in many cases the perceived benefits of SuDS (aesthetics, providing habitat, sustainable drainage solution) outweigh the capital and maintenance costs (Jarvie et al., 2017). Perhaps what is paramount from a biodiversity standpoint is to understand the specific characteristics that make SuDS viable habitats for species such as amphibians, and the chemical and physical barriers that inhibit 
species from colonising and persisting in them. The continued incorporation of SuDS into developing areas can enhance sustainability and improve connections with nature among urban dwellers. However, further evidence to support the merits of SuDS is crucial to facilitating the transition to improved urban water systems.

Scotland has a high rainfall and successful water management strategies are important in urban areas. Glasgow is a post-industrial city with a history of coal mining and heavy industrial manufacturing, and deposits of heavy metals and other pollutants are prevalent. East Kilbride is a region of the greater Glasgow area where amphibian populations have been documented using both natural ponds and SuDS. Paterson (2016) reported on a six-year study of annual variation in amphibian populations in both SuDS and natural ponds, but SuDS only represented six of 33 sites, and no comparisons were made between SuDS and natural ponds regarding amphibian spawning and tadpole development.

This study aimed to test the effects of water quality parameters and urban pollutants on amphibian breeding and development patterns in SuDS and natural ponds in East Kilbride, Scotland. Specifically, we aimed to determine whether: (1) amphibians were present in SuDS sites and if so, which species; (2) there was a difference in water quality between SuDS and natural ponds; (3) water quality or site type influenced common frog (Rana temporaria) breeding activity; and (4) water quality or site type influenced common frog development. The results contribute to the growing body of knowledge relating to how wildlife species use novel water systems in developed areas, which will inform future management decisions.

\section{METHODS}

Study site

An area encompassing water bodies on the outskirts of East Kilbride, South Lanarkshire was chosen for the study site. Nine natural ponds and ten SuDS were selected based on the combination of information obtained from South Lanarkshire Council and knowledge about local amphibian activity in the area (Fig. 1). The Google Earth area calculator tool was employed to determine the area of each site in $\mathrm{m}^{2}$ and was used in conjunction with field observations for sites with tree cover. Each of the 19 sites was visited during the day four times over a period of four months during 2018 (April through July, one visit per month), with two additional night visits in May. Each of the day visits included on-site water quality testing, as well as water sample collection for laboratory analysis. Common frog spawn clump surveys were conducted on the first day visit in April, with tadpole development monitored on subsequent monthly visits. Torchlight surveys to determine frog, toad, and newt presence were conducted on two additional night visits in May. General observations took place at each site during each visit, which included documenting fish presence.

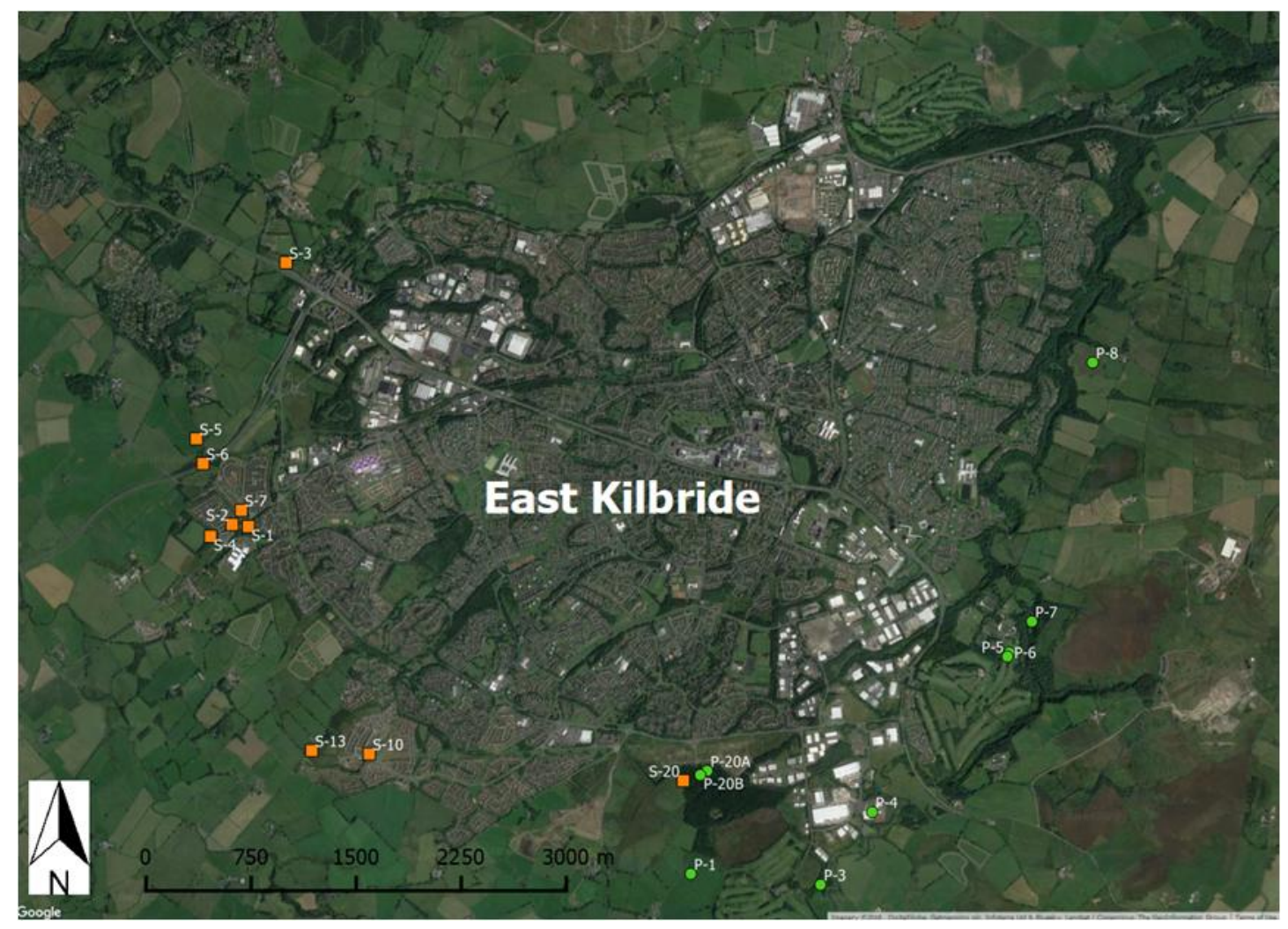

Fig. 1. The East Kilbride, Scotland study site, showing locations of SuDS (orange) and natural ponds (green) surveyed during 2018. 


\section{Water quality analyses}

During each day visit, water quality was tested using a calibrated Hanna HI-98129 combo meter to measure $\mathrm{pH}$ and electrical conductivity (EC). EC is measured in microsiemens per centimetre $(\mu \mathrm{S} / \mathrm{cm})$ and is a measure of a solution's ability to pass an electrical current, so is directly related to the number of ions in a solution. Multiple processes can alter the EC of freshwater, one of which being the application of salt as a road de-icer, which can elevate EC levels of freshwater and result in salt pollution (Sanzo \& Hecnar, 2006; Chambers, 2011; Karraker et al., 2016). Three readings of water quality parameters were taken at each visit and the mean of these values constituted the measurement for each site. Readings were taken at a depth of approximately $10 \mathrm{~cm}$ at the water's edge, and distant from any visible source flowing into the water body.

Water samples were collected for chlorophyll and metal analyses. On each day visit, $500 \mathrm{ml}$ of water was collected from each site for chlorophyll analysis. Samples were stored to inhibit light exposure and ensure no additional photosynthetic activity occurred. Each sample was then filtered within $8 \mathrm{~h}$ through GF/C microfibre filters. Methods by Strickland \& Parsons (1972) were followed, using a Gallenkamp VISI-SPEC spectrophotometer to determine chlorophyll $a$ concentration in $\mu \mathrm{g} \mathrm{l}^{-1}$. An additional $10 \mathrm{ml}$ of water was collected at each site in May, June, and July for analysis of dissolved metal concentrations. Samples were filtered through a Minisart RC $0.45 \mu \mathrm{m}$ filter into $0.1 \mathrm{ml}$ of Aristar nitric acid to form a $1 \%$ nitric acid solution (EPA, 1994). Samples were delivered to the Scottish Universities Environmental Research Centre (SUERC) for inductively coupled plasma atomic emission spectroscopy (ICP-OES) analysis to determine dissolved concentrations of aluminium (Al), copper $(\mathrm{Cu})$, iron (Fe), manganese (Mn), and zinc ( $\mathrm{Zn})$ in $\mu \mathrm{g}$ $\mathrm{l}^{-1}$. Of the five metals, $\mathrm{Cu}, \mathrm{Fe}, \mathrm{Mn}$, and $\mathrm{Zn}$ are "specific pollutants" that are discharged in significant quantities in the U.K. and have potential to negatively impact biological entities (SEPA, 2018). Harmful effects can occur at levels exceeding $1 \mu \mathrm{g} \mathrm{l}^{-1}$ for $\mathrm{Cu}, 1$ $\mathrm{mg} \mathrm{l}^{-1}$ for Fe, $123 \mathrm{\mu g} \mathrm{l}^{-1}$ for $\mathrm{Mn}$, and $10.9 \mu \mathrm{g} \mathrm{l}^{-1}$ for $\mathrm{Zn}$. Aluminium is a "non-statutory" substance as the standards set are not in legislation, but the current standard is $15 \mu^{-1} \mathrm{~g}^{-1}$ (SEPA, 2018).

\section{Amphibian surveying}

During the first visit in April common frog spawn mats were identified. Numbers of common frog spawn clumps were determined using published methods (Griffiths \& Raper 1994), which involved measuring the area of the spawn mat and using the equation $\left(2.27+\left(73 \times\right.\right.$ (spawn mat area in $\left.\left.m^{2}\right)\right)+$ individual clump count) to determine total number of spawn clumps per site. In the subsequent three visits, tadpole development at each site was monitored using Gosner staging (Gosner, 1960). Dip netting was conducted at each site for a duration of
10 min or until 20 tadpoles were caught. Due to the lack of newt and toad tadpoles at most sites surveyed, Gosner staging focused on common frog tadpoles. Torchlight surveys in May consisted of visiting each site following methods described by Griffiths et al. (1996) using a 1,000,000-candlepower Clulite Clubman CB3 LED torch. Torchlight survey data were combined with site observations to generate a measure of presence/absence of common frogs, common toads, and newts (not identified to species) at each site. Fish presence/absence was also recorded.

\section{Statistical analyses}

A generalised linear modelling approach was implemented in $\mathrm{R}$ version 3.4.1 to determine which variables explained the most variation in biological and physical parameters ( $\mathrm{R}$ Core Development Team, 2017). The first set of models aimed to test whether water quality parameters differed significantly by pond type or over time. EC, $\mathrm{pH}$, chlorophyll $a$, and concentrations of each of the heavy metals were used as response variables. Pond type (SuDS or natural pond), date, and type $\mathrm{x}$ date interaction were included as potential variables and likelihood ratio tests were used to test their significance based on stepwise elimination.

The next series of models aimed to explain variation in spawn clump density of common frogs, and presence of spawn clumps in SuDS sites using data collected in April. Two sets of models were created: for the first set, spawn clump counts for each site were divided by the area of the water body in square metres to calculate spawn clump density per site, which was used as the response variable; for the second set, egg presence in SuDS sites was used as a response variable. EC, $\mathrm{pH}$, and chlorophyll $a$ concentrations were treated as covariates in these models, while water body type (SuDS or natural pond), fish presence, newt presence, and toad presence were treated as factors. The EC x type interaction was also considered for the spawn clump density models to determine if differences in EC between water body type could explain variation in spawn clump density. This interaction along with the covariates and factors were included as potential explanatory variables and likelihood ratio tests were used to test their significance based on stepwise elimination.

The final series of models aimed to explain variation in Gosner development stage. The mean Gosner stage characterises the general trend of development for each month and has been used in previous studies pertaining to amphibian development (Walsh et al., 2008, 2016). Gosner stage progression is not a strictly linear phenomenon, but slope can be informative regarding general rate of development as well as mean stage reached when approaching the latter parts of the development season in July (Walsh et al., 2008). 
Thus, two sets of analyses were performed: one using the slope of the three mean Gosner values for sites for which development data were collected in May, June, and July, and one using the final stage of development reached at each site where frog eggs were observed. For these response variables, site type was considered as a factor and EC, $\mathrm{pH}$, heavy metal concentrations, and area of the water body were considered as covariates. Due to the large number of variables considered, relative to the sample size, the final model was determined by successively adding each variable to a simple model and eliminating variables not significantly contributing to the variance, using likelihood ratio tests. For heavy metal concentrations ( $\mathrm{Al}, \mathrm{Cu}, \mathrm{Fe}, \mathrm{Mn}$ and $\mathrm{Zn}$ ), maximum dissolved concentrations across the three sampling periods were determined and percent of the U.K. specific Environmental Quality Standards and Standards for Discharges to Surface Waters (SEPA, 2018) were calculated and used as explanatory variables in the model. In the results section, average rates are shown as mean \pm standard deviation.

For each final model, model fit was tested by calculating percent explained deviance (or pseudo $\mathrm{R}^{2}$ value) using the equation:

$$
\left(\frac{\text { null deviance }- \text { residual deviance }}{\text { null deviance }}\right) \times 100
$$

\section{RESULTS \\ Site characteristics}

There was substantial variation in size of both the SuDS $\left(575 \pm 432.21 \mathrm{~m}^{2}\right)$ and natural ponds $(215 \pm$ $241.57 \mathrm{~m}^{2}$ ) (Table 1). Amphibians were present in all SuDS and natural ponds. Newts were present in eight of the ten SuDS and six of the nine natural ponds, while toads were present in six of the ten SuDS and two of the nine natural ponds (Table 1). Only three SuDS and two natural ponds included fish, which did not appear to be related to size of the sites (Table 1). Two of the 19 sites had no common frog eggs (SuDS \#4 and SuDS \#7), but toads were present in SuDS \#4 and newts were present in SuDS \#7 (Table 1). Since these sites did not contain any frog eggs they were not sampled for tadpoles after April. During July, tadpoles could only be sampled at nine sites due to excessively hot, dry conditions, thus these nine sites were the only ones with Gosner data for all three months (Pond \#3 dried up in July but emerging froglets were seen near moist ground and vegetation and were staged) (Table 1). Therefore, comparisons of water quality parameters in relation to site type and date were based on all 19 sites, assessments of common frog spawn clump densities and maximum amphibian development stage reached were based on 17 sites, and assessment of amphibian development slope was based on nine sites.

\section{Water quality in relation to site type}

On-site water quality testing yielded differences in EC between SuDS and natural ponds, with SuDS generally showing higher levels but more variation in relation to time at some sites (Fig. 2). The EC generalized linear model (GLM) determined that neither the date $x$ site interaction $\left(\chi^{2}=4.11, \mathrm{DF}=3\right.$, $\mathrm{P}$-value $=0.25)$ nor the date $\left(\chi^{2}=1.25, \mathrm{DF}=3, \mathrm{P}\right.$ value $=0.74$ ) were significant in the model, leaving type as the only significant variable and estimating an increase of $236.1 \mu \mathrm{S} / \mathrm{cm}$ for SuDS sites $\left(\chi^{2}=17.41\right.$, $\mathrm{DF}=1$, P-value $=<0.0001$ ) with a pseudo $\mathrm{R}^{2}$ value of 29.49. Chlorophyll a concentrations varied at individual sites (Fig. 6, supplementary information), but no significant differences were found in relation to site type or date. The pH GLM determined that the date $\mathrm{x}$ site interaction was significant $\left(\chi^{2}=15.34\right.$, DF $=3$, P-value $=0.0015$ ), and estimated a $\mathrm{pH}$ decrease in SuDS of 0.28 and 0.43 on 6th April and 7th May respectively, but a $\mathrm{pH}$ increase in SuDS of 0.19 on 7 th July with a pseudo $\mathrm{R}^{2}$ value of 55.06 (Fig. 7, supplementary information).

There was considerable variation between site and date and between the five metals measured (Figs. 812, supplementary information). The date $\mathrm{x}$ type interaction was not significant in any of the GLMs for metal concentrations, and none of the tested terms were significant in explaining aluminium concentration variation. However, type was significant in explaining iron variation with an estimated decrease of $762.2 \mathrm{\mu g} \mathrm{l}^{-1}$ for SuDS, and date was significant in explaining variation in copper ($4.79 \mu \mathrm{g} \mathrm{l}^{-1}$ on 7 th May and $-4.95 \mu \mathrm{g} \mathrm{l}^{-1}$ on 7 th July), manganese $\left(-1066.0 \mu \mathrm{g} \mathrm{l}^{-1}\right.$ on 7 th May and $-715.6 \mu \mathrm{g}$ $\mathrm{l}^{-1}$ on 7 th July), and zinc (-6.95 $\mu \mathrm{g} \mathrm{l}^{-1}$ on 7 th May and $-9.46 \mu \mathrm{g} \mathrm{l}^{-1}$ on 7 th July) (Figs. 8-12, supplementary information).

Variation was also apparent regarding the percent at which the five metals exceeded standards (Fig. 3). For example, most of the sites exceeded standards for aluminium, manganese, and copper, with SuDS \#2 at over $3000 \%$ of the set aluminium standard and SuDS \#10 at over $5000 \%$ of the set manganese standard. Aluminium and manganese concentrations were measured at highly variable magnitudes relative to standards, whereas the highest levels above standards for zinc and iron were less variable at approximately 400-800\%. Most sites were below the zinc and iron set standards, with only two SuDS and two natural ponds exceeding zinc standards, and two SuDS and four natural ponds exceeding iron standards (Fig. 3).

\section{Amphibian breeding in relation to site type and water quality}

Spawn density was on average higher in natural ponds ( $0.70 \pm 0.60$ clumps) compared to SuDS ( 0.16 \pm 0.24 clumps) (Fig. 4). 


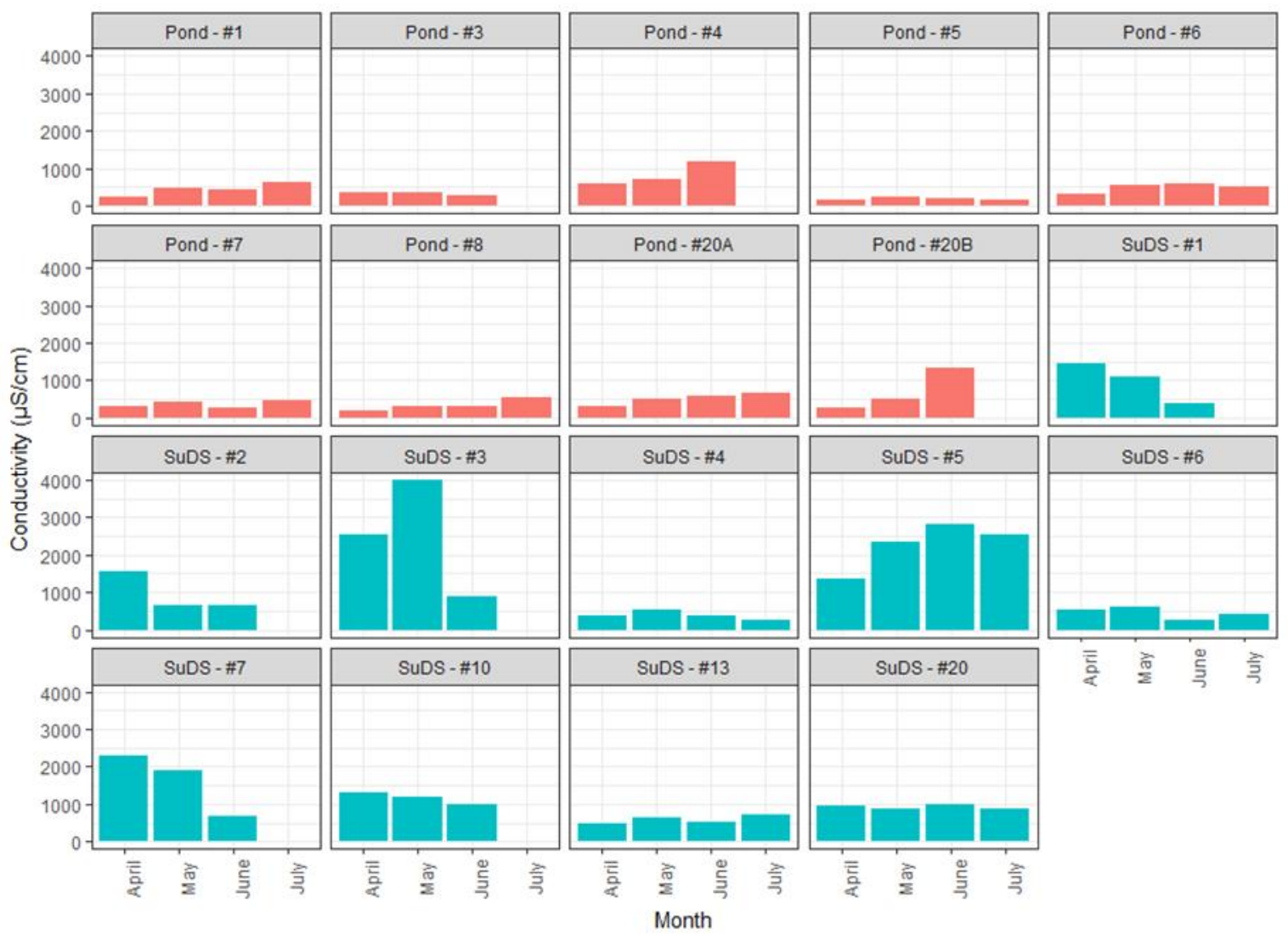

Fig. 2. Electrical conductivity $(\mu \mathrm{S} / \mathrm{cm})$ measured in natural ponds (red bars) and SuDS (blue bars) surveyed at East Kilbride, Scotland on 6th April, 7th May, 3rd June, and 7th July 2018.
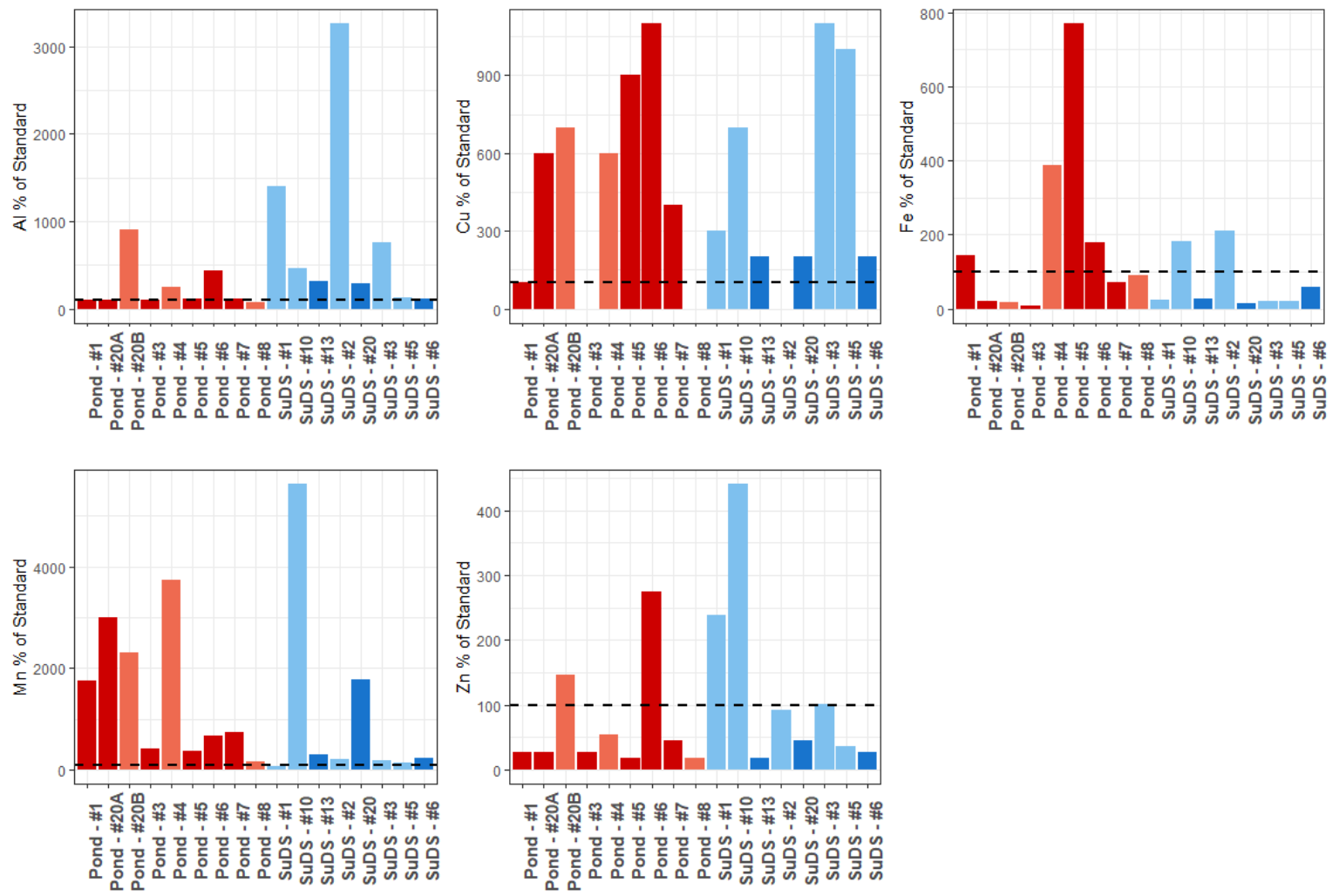

Fig. 3. Concentration percent exceeding the maximum U.K. surface water standards for five heavy metals (aluminium, copper, iron, manganese and zinc) at natural ponds and SuDS at East Kilbride, Scotland surveyed during 2018. Six natural ponds sampled over three months (dark red bars) and three natural ponds not sampled over all three months (pale red bars). Three SuDS sampled over all three months (dark blue bars), and five SuDS not sampled over all three months (light blue bars). Black dashed line denotes the U.K. surface water standard for each metal at $100 \%$. 

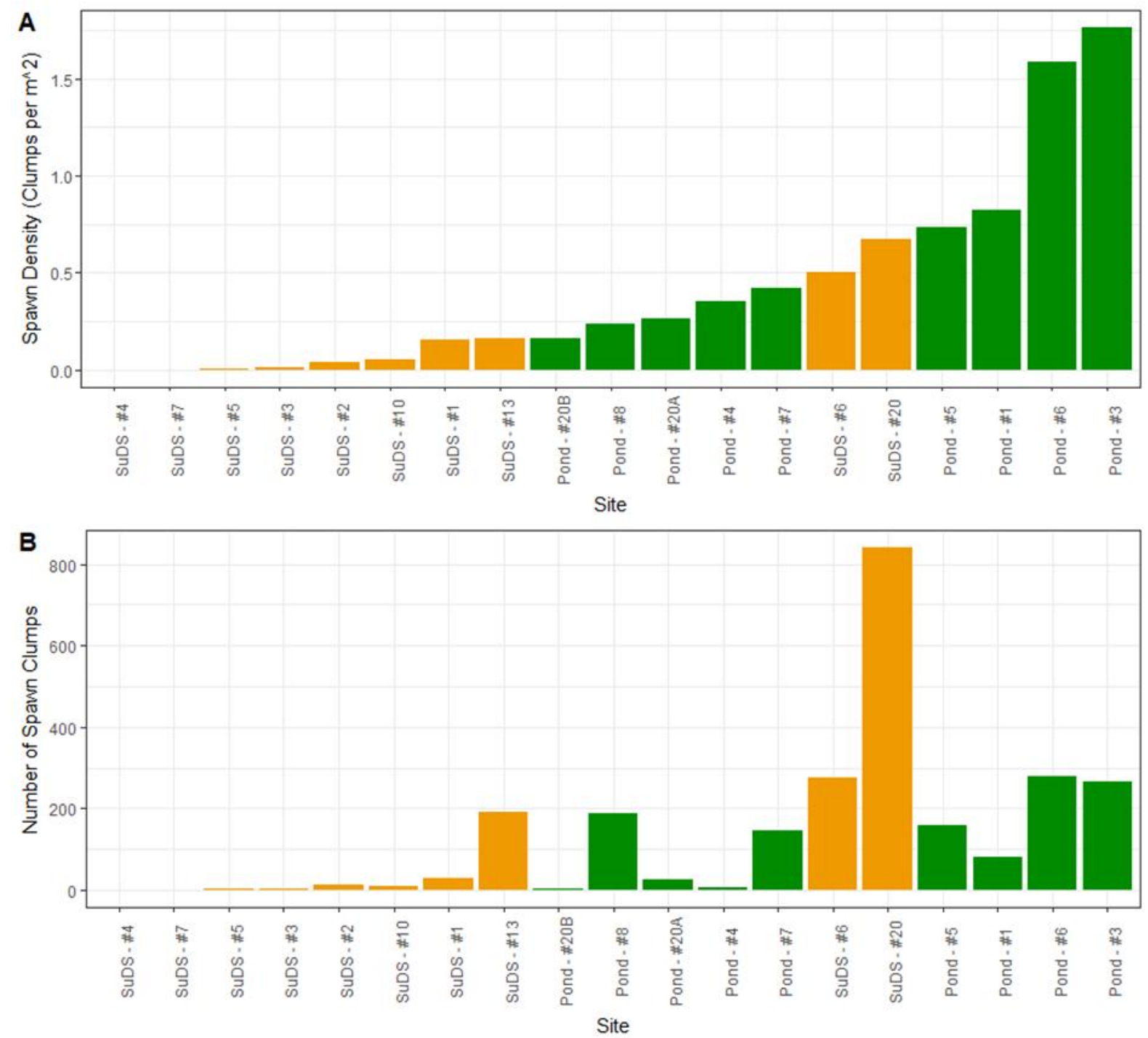

Fig. 4. Common frog (Rana temporaria) spawn densities (clumps per $\mathrm{m}^{2}$ ) (A) and number of spawn clumps (B) at SuDS (yellow bars) and natural ponds (green bars) at East Kilbride, Scotland surveyed during 2018. Spawn densities are arranged by ascending order of density, and spawn clumps are arranged in the same order as density.

Site type was the only significant variable explaining variation in spawn density $\left(\chi^{2}=6.09, \mathrm{DF}=1, \mathrm{P}\right.$-value $=0.014$ ), with a predicted decrease in spawn density of 0.54 clumps per square metre in SuDS. The pseudo $\mathrm{R}^{2}$ value for the model was calculated at 29.49 , indicating a small proportion of variation was explained. Pond \#3 had the highest spawn density with over 1.75 clumps per $\mathrm{m}^{2}$, while the lowest eight spawn densities belonged to SuDS sites (Fig. 4). Although spawn densities were on average greater in natural ponds compared to SuDS, the mean spawn counts were slightly higher in SuDS (136.7 \pm 265.24$)$ than natural ponds $(128.33 \pm 105.27)$ due to SuDS \#20 which had excess of 800 spawn clumps (Fig. 4). For SuDS site egg presence, none of the water quality parameters, newt presence, or toad presence were significant in explaining variation; however, fish presence was significant $\left(\chi^{2}=6.19, \mathrm{DF}=1, \mathrm{P}\right.$-value $=0.013$ ), with an estimated 21.26 lower probability of egg presence when fish were present (Table 1).

\section{Amphibian development in relation to site type and water quality}

Based on the nine sites that could be sampled for tadpoles over the three months, tadpoles in SuDS had higher development rates than those in natural ponds (Table 1). The maximum Gosner value for July was 46 which represented froglets observed around the perimeter of the site that had completed metamorphosis with tails fully resorbed, and all but two of the nine sites had individuals at this stage by the July sampling period (Table 1 ). Pond \#5 showed a maximum of 45 (froglets with tail not fully resorbed), but tadpoles at Pond \#6 (which showed some of the highest signs of pollution based on the heavy metal analyses; Fig. 3) only reached stage 38 (hindlimb toe differentiation, forelimbs not emerged) by July. The froglets observed at pond \#3 and SuDS \#6 were the most developed, with all individuals reaching stage 46 by the July sampling period. 


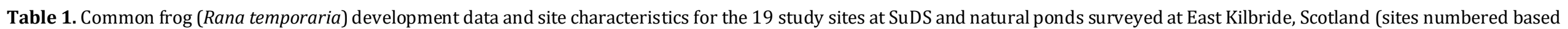

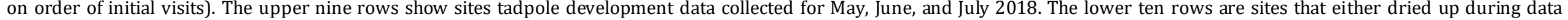
collection so development data were not collected for all three months, or no frog eggs were observed during April.

\begin{tabular}{|c|c|c|c|c|c|c|c|c|c|c|c|c|c|}
\hline & Site ID & $\begin{array}{l}\text { Frog egg } \\
\text { Presence }\end{array}$ & $\begin{array}{l}\text { Site } \\
\text { Dried } \\
\text { in } \\
\text { July }\end{array}$ & $\begin{array}{l}\text { Mean } \\
\text { May } \\
\text { Gosner } \\
\text { Stage }\end{array}$ & $\begin{array}{l}\text { Mean } \\
\text { June } \\
\text { Gosner } \\
\text { Stage }\end{array}$ & $\begin{array}{l}\text { Mean } \\
\text { July } \\
\text { Gosner } \\
\text { Stage }\end{array}$ & $\begin{array}{l}\text { Min./Max. } \\
\text { Gosner } \\
\text { Stage } \\
\text { observed } \\
\text { in July }\end{array}$ & $\begin{array}{l}\text { Max. } \\
\text { Gosner } \\
\text { Stage } \\
\text { reached }\end{array}$ & $\begin{array}{l}\text { Gosner } \\
\text { Slope }\end{array}$ & $\begin{array}{l}\text { Area } \\
\left(\mathbf{m}^{2}\right)\end{array}$ & $\begin{array}{l}\text { Fish } \\
\text { Presence }\end{array}$ & $\begin{array}{l}\text { Newt } \\
\text { Presence }\end{array}$ & $\begin{array}{l}\text { Toad } \\
\text { Presence }\end{array}$ \\
\hline \multirow{9}{*}{ 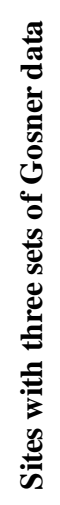 } & Pond \#1 & Yes & No & 25.4 & 35.2 & 44 & $39 / 46$ & 46 & 9.3 & 100 & No & Yes & No \\
\hline & Pond \#3 & Yes & Yes & 26.9 & 36.2 & 46 & $46 / 46$ & 46 & 9.55 & 150 & No & Yes & No \\
\hline & Pond \#5 & Yes & No & 25.2 & 32.4 & 38.3 & $36 / 45$ & 45 & 6.55 & 215 & No & Yes & No \\
\hline & Pond \#6 & Yes & No & 25.2 & 29.5 & 33.2 & $28 / 38$ & 38 & 4.00 & 175 & Yes & No & No \\
\hline & Pond \#7 & Yes & No & 25.75 & 37.33 & 42.8 & $39 / 46$ & 46 & 8.53 & 350 & Yes & No & No \\
\hline & Pond \#20A & Yes & No & 26.95 & 39.9 & 42.3 & $37 / 46$ & 46 & 7.68 & 100 & No & Yes & Yes \\
\hline & SuDS \#6 & Yes & No & 25.2 & 40 & 46 & $46 / 46$ & 46 & 10.40 & 550 & No & Yes & Yes \\
\hline & SuDS \#13 & Yes & No & 27 & 38.2 & 45.8 & $45 / 46$ & 46 & 9.40 & 1200 & No & Yes & Yes \\
\hline & SuDS \#20 & Yes & No & 25.8 & 35.5 & 45.7 & $45 / 46$ & 46 & 9.95 & 1250 & Yes & Yes & Yes \\
\hline \multirow{10}{*}{ 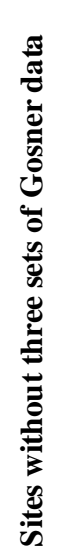 } & Pond \#4 & Yes & Yes & 25.1 & -- & -- & -- & 26 & -- & 20 & No & No & No \\
\hline & Pond \#8 & Yes & Yes & 26 & 29 & -- & -- & 29 & -- & 800 & No & Yes & No \\
\hline & Pond \#20B & Yes & Yes & 26.2 & -- & -- & -- & 27 & -- & 25 & No & Yes & Yes \\
\hline & SuDS \#1 & Yes & Yes & 25 & 41 & -- & -- & 41 & -- & 200 & No & Yes & No \\
\hline & SuDS \#2 & Yes & Yes & -- & -- & -- & -- & -- & -- & 300 & No & Yes & No \\
\hline & SuDS \#3 & Yes & Yes & -- & -- & -- & -- & -- & -- & 150 & No & Yes & Yes \\
\hline & SuDS \#4 & No & No & -- & -- & -- & -- & -- & -- & 900 & Yes & No & Yes \\
\hline & SuDS \#5 & Yes & Yes & -- & -- & -- & -- & -- & -- & 800 & No & Yes & Yes \\
\hline & SuDS \#7 & No & No & -- & -- & -- & -- & -- & -- & 200 & Yes & Yes & No \\
\hline & SuDS \#10 & Yes & Yes & 26.5 & -- & -- & -- & 27 & -- & 200 & No & No & No \\
\hline
\end{tabular}


The minimum Gosner value for July varied more substantially between sites, with the least developed individual seen at stage 28 (hindlimbs at budding stage, no toe differentiation), which was also observed at pond \#6. All except one of the natural ponds (\#3) showed slower developing tadpoles than the three SuDS sites based on slope (Table 1). Pond \#6 also showed a substantially lower Gosner slope (4.0) across the three sampling points than the other sites (maximum of 10.4 in SuDS \#6) and natural ponds on average showed a lower slope $(7.60 \pm 2.08)$ than the SuDS sites $(9.92 \pm 0.50)$. Therefore, differences in the slowest developing tadpoles influenced the mean Gosner stage in July, with the lowest values at 33.2 (pond \#6) and 38.3 (pond \#5), and the highest value at 46 (pond \#3 and SuDS \#6).

Of the ten remaining sites that did not have complete Gosner data for the three months, two had no frog eggs (SuDS \#4 and SuDS \#7), tadpoles were not detected at three (SuDS\#2, SuDS \#3, and SuDS \#5), tadpoles were only detected in May for three (pond \#4, pond \#20B, and SuDS \#10), and tadpoles were detected in May and June in two (pond \#8 and SuDS \#1) (Table 1). The highest maximum Gosner stage of these ten sites was observed in June at stage 41 (SuDS \#1), while the lowest was observed in May at stage 26 (pond \#4). The three sites where eggs were observed but no tadpoles were detected were SuDS (\#2, \#3, and \#5). SuDS \#2 showed extremely high levels of aluminium (excess of $3000 \%$ of the set standard) and high levels of Fe; SuDS \#3 showed high EC levels (higher than the maximum detectable by the water quality meter at over $3999 \mu \mathrm{S} / \mathrm{cm}$ in May), high aluminium and copper levels; and SuDS \#5 showed high EC levels and high copper levels (Figs. 2, 3).

Based on the GLM model selection, site type, area of the water body, and percent of U.K. standard for maximum aluminium, copper, and zinc concentration were significantly associated with variation in the slope of Gosner stages (as a proxy for developmental rate) for the nine sites that were sampled over all three months. The GLM estimated a Gosner slope increase of 0.86 in SuDS, 0.0015 with area, and 0.0049 with percent of U.K. standard for maximum zinc concentration, but a decrease of 0.0034 with percent of U.K. standard for maximum copper concentration and 0.0095 with percent of U.K. standard for maximum aluminium concentration. The pseudo $\mathrm{R}^{2}$ value for this model was 99.94, indicating a very strong fit and explaining most of the variation. Based on the maximum Gosner GLM model selection, site type, average EC levels for the four sampling dates, and percent of U.K. standard for maximum aluminium concentration were significantly associated with variation in the maximum Gosner stage reached for the 17 sites that had frog eggs. The GLM estimated a maximum Gosner stage increase of 9.022 in SuDS, and a decrease of 0.022 with average EC level and 0.013 with percent of U.K. standard for maximum aluminium concentration. The pseudo $\mathrm{R}^{2}$ value for this model was 85.64, indicating a strong fit and explaining most of the variation.

\section{DISCUSSION}

The results presented here indicate that SuDS were similar to natural ponds in terms of amphibian presence, with all sites having at least one amphibian species detected, and most sites (79\%) having multiple amphibian species (Table 1). Variation in water quality parameters was apparent, but the only significant differences in pollutants based on site type were EC and iron levels, while most others varied based on date of collection (Figs. 6-12, supplementary information). Common frogbreeding was not associated with water quality parameters, but rather with site type, as natural ponds facilitated significantly higher breeding densities than SuDS. Moreover, frog egg presence was negatively associated with fish presence within SuDS sites. Amphibian development was significantly associated with variation in water quality parameters; sites with hindered or aborted development tended to have high indicators of pollutant levels (Table 1; Figs. 3, 4), which suggests an increased susceptibility of tadpoles to multiple pollutants. Overall, multiple sites in the sampling area had low levels of pollutants, as well as productive breeding and development rates regardless of site type, demonstrating that both natural ponds and SuDS are important habitat for amphibians in East Kilbride.

\section{Water quality differences in SuDS and natural ponds}

A major difference between SuDS and natural ponds relates to proximity to roads and developed areas. A primary goal of the SuDS design is to manage surface water and incorporate sustainable designs around urban and suburban areas (Woods Ballard et al., 2015). The natural ponds in this study were more isolated from major roads than were SuDS, and there was also a difference in geographic location based on site type (Fig. 1). Natural ponds were located to the southeast of the study area while SuDS were to the southwest, which represents a potential confounding effect. However, differences between SuDS \#20, and ponds \#20A and \#20B were apparent even though they were situated in very close proximity, suggesting that differences between SuDS and natural ponds were based on characteristics of the ponds and not just geographic location. The protracted winter weather and unusual snowfall during the early months of 2018 may have resulted in administering road salts at an intensified rate throughout the greater Glasgow area. Salinity and conductivity levels of waterways adjacent to roads and developed areas probably increased initially, and heightened levels may have persisted if salt deposits formed and dissolved repeatedly during precipitation events. Gallagher et al. (2014) reported 
urban pond chloride levels exceeding toxicity guidelines, and the highest EC value from this study was recorded in SuDS \#7 during May, at over 3999 $\mu \mathrm{S} / \mathrm{cm}$. Increased mortality, increased severity and frequency of developmental deformities, heightened stress levels, and reduced activity are among the harmful effects salts can have on amphibians. Thus solutions to abate de-icers or partition roads from nearby aquatic habitats can assist in maintaining ecological integrity and prevent salt pollution (Sanzo \& Hecnar, 2006; Collins \& Russell, 2009; Chambers, 2011; Hopkins et al., 2013; Hua \& Pierce, 2013). Isolating aquatic habitats from roads and developed areas may also prevent metal pollution, as heavy metals in urban waterways often originate from transportation areas and vehicles (Allen et al., 2017a; White et al., 2017). Another possible source of elevated metal concentrations may be the submerged refuse observed at sites, including cans, pipes, trollies, bicycles, engine parts, which could leach metals into these environments.

\section{Factors affecting amphibian breeding}

Common frog spawn clump densities were higher in natural ponds than in SuDS, which suggests that in general the natural ponds offer conditions that were more favourable than SuDS. Natural ponds may be more attractive to amphibians because SuDS are artificially developed for drainage and tend to be nearer to homogenous, impervious landscapes (Birx-Raybuck et al., 2010; Woods Ballard et al., 2015; Guderyahn et al., 2016). However, more evidence is necessary as the pseudo $\mathrm{R}^{2}$ value for the spawn density model was 29.49, indicating that some of the variation was explained but other unknown factors besides site type are likely influencing spawn clump density. Holzer (2014) also found that whether the site was natural or constructed only had a weak association with native amphibian breeding, whereas forest cover and prevalence of aquatic vegetation had a stronger association. Habitat characteristics such as vegetation, impervious surfaces, and shading could be important regarding amphibian breeding and perhaps could have explained some of the variation in breeding between SuDS and natural ponds.

Overall, there was no association of egg absence with water quality parameters, so other environmental characteristics associated with SuDS may deter amphibians from breeding in these sites. All the SuDS sites were at least ten years old (South Lanarkshire Council), indicating that age of the SuDS is probably not a contributing factor to reduced use by amphibians. Although the sample size is small, the presence of fish was associated with the absence of frog eggs in SuDS and may have deterred breeding at these sites. Avoidance of amphibians breeding in water bodies with fish is documented and has been associated with decreased anuran diversity (Drake et al., 2015; Manenti \& Pennati, 2016; Pollard et al., 2017). However, both natural pond sites with fish had frog spawn, indicating fish may have a more inhibiting effect on breeding in SuDS than in natural ponds, although a larger sample size is necessary to confirm this.

\section{Factors affecting amphibian development}

Gosner slope as well as maximum Gosner stage both significantly increased at SuDS sites, suggesting that SuDS had developmentally favourable characteristics. However, the results suggest that the presence of particular or combinations of heavy metals might negatively affect amphibian development. The amount by which aluminium exceeded standards was associated with both decreased Gosner slope and decreased maximum Gosner stage, indicating a negative effect on development. Aluminium toxicity to wood frog tadpoles (Rana sylvatica) significantly decreased body mass as well as protracted development (Peles, 2013). A similar toxic effect may have hindered development of common frog tadpoles in this study. Aluminium was the only metal negatively associated with both Gosner slope and maximum Gosner staged reached. The results suggest that other pollutants that hinder development may work in tandem when in high concentrations.

Of the nine sites having Gosner stage data for May, June, and July, pond \#6 had the shallowest Gosner slope and the lowest mean Gosner stage for July at 33.2 , the next highest mean being 38.3 (pond \#5) and all other sites above 42 (Table 1). Pond \#6 had the highest levels of aluminium, copper, and zinc, as well as being above the U.K. standards for all five of the heavy metals tested (Fig. 3) while pond \#5 had the highest concentration of $\mathrm{Fe}$, at $770 \%$ of the U.K. standard, but also had elevated copper and manganese levels. This could suggest that elevated levels of multiple heavy metals were hindering tadpole development and growth at these sites. Furthermore, fish were present in pond \#6, which may have induced higher stress levels in tadpoles, as a consistent field observation was tail damage to tadpoles where fish were present. Combinations of pollutants at high levels may also explain the lack of tadpoles where eggs were present in SuDS \#2, \#3, and \#5 (Figs. 2, 3), and may be indicative of aborted development. Chen et al. (2007) found that exposure to elevated copper levels reduced northern leopard frog (Rana pipiens) tadpole growth as well as increasing time to metamorphosis. It has also been demonstrated that American bullfrog tadpoles (Lithobates catesbeianus) exposed to iron and manganese resulted in delayed time to metamorphosis (Veronez et al., 2016). The negative effect of heavy metals on tadpole development that we found is consistent with current research, and multiple heavy metals may have a compounding hindering effect. 
Atypical Scottish weather patterns of 2018 Abnormal weather patterns were observed in Scotland during spring and summer of 2018. Glasgow received $40.6 \mathrm{~cm}$ of snow between 28th February and 1st March and temperatures were below $0^{\circ} \mathrm{C}$ on 10 days (AccuWeather.com). During April, temperatures did not exceed $11^{\circ} \mathrm{C}$ until the 14 th. Temperatures began to rise during late May, where the average high temperature for the last eight days of the month was $22^{\circ} \mathrm{C}$. June received continued warm weather and exceeded $30^{\circ} \mathrm{C}$ for two days during the last week. The warm weather continued in July, with 22 of the 31 days receiving a maximum temperature of at least $20^{\circ} \mathrm{C}$. Rainfall also diminished, as recorded levels in 2018 were less than average in April (by $13 \mathrm{~mm}$ ), May (36 mm), June (20 mm), and July (47 mm) (AccuWeather.com).

The effect of this warm temperature and low rainfall was seen at many of the survey sites. Sites with large numbers of tadpoles during May (Pond \#4, pond \#20B, and SuDS \#10) were devoid of tadpoles in June. Hydroperiod is especially important for most breeding amphibians, as standing water is needed for initial spawning and aquatic larvae development. Longer hydroperiods are thus advantageous for amphibians because they support larger breeding populations and higher species richness (Baldwin et al., 2006; Holtmann et al., 2017).

The high temperatures and lack of rainfall during 2018 resulted in substantial site drying, as eight of the 19 sites (two natural ponds, six SuDS) had desiccated enough to eliminate all standing water, or rendering the site inaccessible in July (Table 1 ). The high temperature could have accelerated development in tadpoles, as laboratory experiments revealed that increased temperatures resulted in increased development in common frogs compared to lower temperatures (Walsh et al., 2016). Although we did not have comparable data to compare with other years, the variation in Gosner slope documented in this study suggests that other factors also changed developmental rates.

\section{Management implications}

During times of drought or unusually warm and dry weather, a potential management solution to pond drying is to extend hydroperiod by manually adding water. Seigel et al. (2006) documented a considerable decrease in tadpole mortality and increase in metamorphosis in a pond supplemented by well water to increase hydroperiod. Very limited research has addressed this topic and supplementing surface water bodies with ground water or other water sources may alter their composition with unknown consequences. The drying of multiple SuDS sites due to warm weather and lack of rain has design implications, and it is recommended that SuDS being developed in the future consider a minimum area to avoid drying and potential harm to wildlife. All SuDS $300 \mathrm{~m}^{2}$ or less dried completely or to the point of water inaccessibility (Fig. 5); thus, it is recommended that future SuDS designs be built to a size of at least 400 $\mathrm{m}^{2}$. Smaller SuDS designs risk desiccation during unusual bouts of heat such as those seen during this study, and hydroperiod and the ability of artificial ponds to retain water can have major effects on amphibian communities (Hamer \& McDonnell, 2008). Although amphibian adults and newly metamorphosed individuals may be able to survive in moist and vegetated areas after pond drying, a major risk is posed for tadpoles in these conditions, as they require adequate standing water to develop.

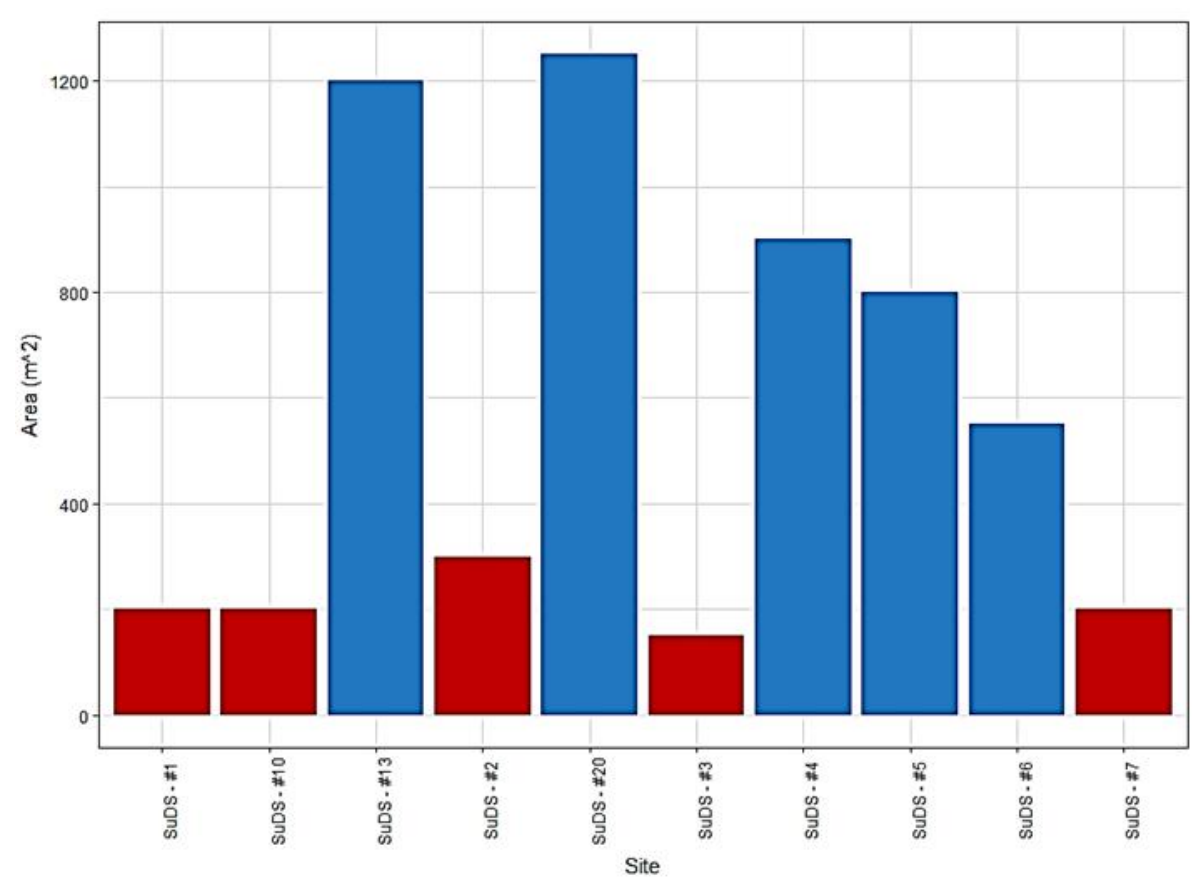

Fig. 5. Surveyed SuDS based on area $\left(\mathrm{m}^{2}\right)$ at East Kilbride, Scotland during 2018. SuDS that dried out during July (red bars), and SuDS which did not dry out (blue bars). 
The amphibian assemblages present in all ten SuDS from this study exemplify their viability as amphibian habitat and importance in a continually urbanising environment. Common frogs were present and bred in eight of the ten SuDS, which is comparable to a study in Inverness, Scotland where common frogs were present and bred in eight of 12 SuDS in 2011 and 2012 (O'Brien, 2015). However, in our study three of these eight SuDS with breeding activity showed no signs of tadpoles, and one site had tadpoles only in May, suggesting that water quality or other aspects of these sites might not have been as suitable as perceived during breeding. The function of SuDS and other urban drainage systems to sequester pollutants increases their potential to be ecological traps by advertising false cues of suitable habitat (Battin, 2004; Robertson \& Hutto, 2006). Ecological traps are a major risk for wildlife in urban areas, but frequent management of SuDS and systematic monitoring and removal of harmful pollutants are one method to ensure these habitats stay suitable and not acquire toxic pollutant levels. Additionally, the installation of vegetation buffer zones around urban drainages can be advantageous for amphibians by creating habitat and potentially sequestering heavy metals through phytoremediation (Birx-Raybuck et al., 2010; Moreira et al., 2011; Puglis \& Boone, 2012; Holzer, 2014). Low levels of contaminants and productive breeding activity was seen in some East Kilbride SuDS, which is encouraging. However, more research is required to identify the conditions that make artificial systems habitable, and long-term studies are necessary to illuminate annual and seasonal variations in pollutants and how these conditions influence successful amphibian breeding and development. Research such as this will add to the growing body of knowledge pertaining to the importance of artificial water bodies for wildlife.

\section{ACKNOWLEDGEMENTS}

We would like to thank Gillian MacKinnon for advice and assistance with metal analyses, Sofie Spatharis for advice and use of facilities, Louisa Maddison for providing information about East Kilbride SuDS, and Margaret Packer for assistance and information during laboratory work. A short preliminary version of this work was presented at the conference Amphibians and Reptiles of Scotland: current research and future challenges on 9th June 2018. The authors thank the proceedings editor for the opportunity to present the results here.

\section{REFERENCES}

AccuWeather.com. (2018). Glasgow, United Kingdom.

https://www.accuweather.com/en/gb/glasgow /g3-8/april-

weather $/ 328226$ ? monyr=4/1/2018\&view=tabl e (Accessed 1 August 1 2018)

Allen, D., Arthur, S., Haynes, H. \& Olive, V. (2017a). Multiple rainfall event pollution transport by sustainable drainage systems: The fate of fine sediment pollution. International Journal of Environmental Science and Technology 14, 639652.

Allen, D., Haynes, H. \& Arthur, S. (2017b). Contamination of detained sediment in sustainable urban drainage systems. Water 9, 355. DOI:10.3390/w9050355

Baldwin, R.F., Calhoun, A.J.K. \& DeMaynadier, P.G. (2006). The significance of hydroperiod and stand maturity for pool-breeding amphibians in forested landscapes. Canadian Journal of Zoology 84, 1604-1615.

Battin, J. (2004). When Good Animals Love Bad Habitats : Ecological Traps and the Conservation of Animal Populations. Conservation Biology 18, 1482-1491.

Birx-Raybuck, D.A., Price, S.J. \& Dorcas, M.E. (2010). Pond age and riparian zone proximity influence anuran occupancy of urban retention ponds. Urban Ecosystems 13, 181-190.

Bradford, D.F., Swanson, C. \& Gordon, M.S. (1994). Effects of low $\mathrm{pH}$ and aluminum on amphibians at high elevation in the Sierra Nevada, California. Canadian Journal of Zoology 72, 1272-1279.

Brand, A.B. \& Snodgrass, J.W. (2010). Value of artificial habitats for amphibian reproduction in altered landscapes. Conservation Biology 24, 295301.

Burgett, A. \& Wright, C. (2007). Impact of ammonium nitrate on wood frog (Rana sylvatica) tadpoles: effects on survivorship and behavior. Herpetological Conservation and Biology 2, 29-34.

Carignan, V. \& Villard, M.A. (2002). Selecting indicator species to monitor ecological integrity: a review. Environmental Monitoring and Assessment 78, 45-61.

Chambers, D.L. (2011). Increased conductivity affects corticosterone levels and prey consumption in larval amphibians. Journal of Herpetology 45, 219-223.

Chen, T.H., Gross, J. \& Karasov, W.H. (2007). Adverse effects of chronic copper exposure in larval northern leopard frogs (Rana pipiens). Environmental Toxicology and Chemistry/SETAC 26, 1470-1475.

Collins, S.J. \& Russell, R.W. (2009). Toxicity of road salt to Nova Scotia amphibians. Environmental Pollution 157, 320-324.

Drake, D.L., Ousterhout, B.H., Johnson, J.R., Anderson, T.L., Peterman, W.E., Shulse, C.D. et al. (2015). Pond-breeding amphibian community composition in Missouri. American Midland Naturalist 174, 180-187.

Earl, J.E. \& Whiteman, H.H. (2010). Evaluation of Phosphate Toxicity in Cope's Gray Treefrog (Hyla chrysoscelis) Tadpoles. Journal of Herpetology 44, 201-208.

EPA. (1994) Determination of metals and trace elements in water and wastes by inductively coupled plasma-atomic emission spectrometry. Method 200.7 Revision 4, Revision 4.4. 
Gallagher, M.T., Snodgrass, J.W., Brand, A. B., Casey, R.E., Lev, S.M. \& Van Meter, R.J. (2014). The role of pollutant accumulation in determining the use of stormwater ponds by amphibians. Wetlands Ecology and Management 22, 551-564.

Garnache, C., Swinton, S.M., Herriges, J.A., Lupi, F. \& Stevenson, R.J. (2016). Solving the phosphorus pollution puzzle: Synthesis and directions for future research. American Journal of Agricultural Economics 98, 1334-1359.

Gensemer, R.W. \& Playle, R.C. (1999). The bioavailability and toxicity of aluminum in aquatic environments. Critical Reviews in Environmental Science and Technology 29, 315450.

Gosner, K.L. (1960). A simplified table for staging anuran embryos larvae with notes on identification. Herpetologica 16, 183-190.

Griffiths, R. \& Raper, S. (1994). How many clumps are there in a mass of frog spawn. British Herpetological Bulletin 50, 14-17.

Griffiths, R., Raper, S.J. \& Brady, L. (1996). Evaluation of a standard method for surveying common frogs (Rana temporaria) and newts (Triturus cristatus, T. helveticus and T. vulgaris). JNCC Report 259, 33.

Guderyahn, L.B., Smithers, A.P. \& Mims, M.C. (2016). Assessing habitat requirements of pondbreeding amphibians in a highly urbanized landscape: Implications for management. Urban Ecosystems 19, 1801-1821.

Guo, L. (2007). Doing battle with the green monster of Taihu Lake. Science 317, 1166.

Hamer, A.J. \& McDonnell, M.J. (2008). Amphibian ecology and conservation in the urbanising world: A review. Biological Conservation 141, 2432-2449.

Hamer, A.J., Smith, P.J. \& McDonnell, M.J. (2012). The importance of habitat design and aquatic connectivity in amphibian use of urban stormwater retention ponds. Urban Ecosystems 15, 451-471.

Holtmann, L., Philipp, K., Becke, C. \& Fartmann, T. (2017). Effects of habitat and landscape quality on amphibian assemblages of urban stormwater ponds. Urban Ecosystems 20,1249-1259.

Holzer, K.A. (2014). Amphibian use of constructed and remnant wetlands in an urban landscape. Urban Ecosystems 17, 955-968.

Hopkins, G.R., French, S.S. \& Brodie, E.D. (2013). Increased frequency and severity of developmental deformities in rough-skinned newt (Taricha granulosa) embryos exposed to road deicing salts $(\mathrm{NaCl} \& \mathrm{MgCl} 2)$. Environmental Pollution 173, 264-269.

Hua, J. \& Pierce, B.A. (2013). Lethal and sublethal effects of salinity on three common texas amphibians. Copeia 2013, 562-566.

Jarosiewicz, A., Radawiec, B. \& Hetmański, T. (2014). Influence of water chemistry and habitat parameters on the abundance of pond-breeding amphibians. Polish Journal of Environmental
Studies 23, 349-355.

Jarvie, J., Arthur, S. \& Beevers, L. (2017). Valuing multiple benefits, and the public perception of SUDS ponds. Water 9, 128. DOI: $10.3390 /$ w9020128

Johnson, P.T.J. \& Chase, J.M. (2004). Parasites in the food web: Linking amphibian malformations and aquatic eutrophication. Ecology Letters 7, 521526.

Johnson, P.T.J., Chase, J.M., Dosch, K.L., Hartson, R.B., Gross, J.A., Larson, D.J. et al. (2007). Aquatic eutrophication promotes pathogenic infection in amphibians. Proceedings of the National Academy of Sciences 104, 15781-15786.

Karraker, N.E., Gibbs, J.P. \& And Vonesh, J.R. (2016). Impacts of road deicing salt on the demography of vernal pool-breeding amphibians. Ecological Applications 18, 724-734.

Lefcort, H., Meguire, R.A., Wilson, L.H. \& Ettinger, W.F. (1998). Heavy metals alter the survival, growth, metamorphosis, and antipredatory behavior of Columbia spotted frog (Rana luteiventris) tadpoles. Archives of Environmental Contamination and Toxicology 35, 447-456.

Manenti, R. \& Pennati, R. (2016). Environmental factors associated with amphibian breeding in streams and springs: Effects of habitat and fish occurrence. Amphibia Reptilia 37, 237-242.

Moreira, H., Marques, A.P.G.C., Rangel, A.O.S.S. \& Castro, P.M.L. (2011). Heavy metal accumulation in plant species indigenous to a contaminated Portuguese site: Prospects for phytoremediation. Water, Air, and Soil Pollution 221, 377-389.

O’Brien, C.D. (2015). Sustainable drainage system (SuDS) ponds in Inverness, UK and the favourable conservation status of amphibians. Urban Ecosystems 18, 321-331.

Paterson, E. (2016). Annual variation in the numbers of breeding common frog Rana temporaria at a cluster of sites in the west of Scotland. The Glasgow Naturalist 26(3), 25-31.

Peles, J.D. (2013). Effects of chronic aluminum and copper exposure on growth and development of wood frog (Rana sylvatica) larvae. Aquatic Toxicology 140-141, 242-248.

Perkins, R.G. \& Underwood, G.J.C. (2002). Partial recovery of a eutrophic reservoir through managed phosphorus limitation and unmanaged macrophyte growth. Hydrobiologia 481, 75-87.

Pollard, C.J., Stockwell, M.P., Bower, D.S., Garnham, J.I., Pickett, E.J., Darcovich, K. et al. (2017). Removal of an exotic fish influences amphibian breeding site selection. Journal of Wildlife Management 81, 720-727.

Polo-Cavia, N., Burraco, P. \& Gomez-Mestre, I. (2016). Low levels of chemical anthropogenic pollution may threaten amphibians by impairing predator recognition. Aquatic Toxicology 172, 30-35.

Puglis, H.J. \& Boone, M.D. (2012). Effects of terrestrial buffer zones on amphibians on golf courses. PLOS ONE 7, e39590.

R Core Development Team (2017). R: a language and 
environment for statistical computing. $\mathrm{R}$ Foundation for Statistical Computing, Vienna, Austria. https://www.r-project.org/

Robertson, B.A. \& Hutto, R.L. (2006). A framework for understanding ecological traps and an evaluation of existing evidence. Ecological Society of America 87, 1075-1085.

Sanzo, D. \& Hecnar, S.J. (2006). Effects of road deicing salt $(\mathrm{NaCl})$ on larval wood frogs (Rana sylvatica). Environmental Pollution 140, 247-256.

Scheffers, B.R. \& Paszkowski, C.A. (2012). The effects of urbanization on North American amphibian species: Identifying new directions for urban conservation. Urban Ecosystems 15, 133-147.

Scottish Environment Protection Agency (SEPA). (2018). Supporting Guidance (WAT-SG-53) Environmental Standards for Discharges to Surface Waters.

https://www.sepa.org.uk/media/152957/watsg-53-environmental-quality-standards-fordischarges-to-surface-waters.pdf

Seigel, R.A., Dinsmore, A. \& Richter, S.C. (2006). Using well water to increase hydroperiod as a management option for pond-breeding amphibians. Wildlife Society Bulletin 34, 10221027.

Snodgrass, J.W., Casey, R.E., Joseph, D. \& Simon, J.A. (2008). Microcosm investigations of stormwater pond sediment toxicity to embryonic and larval amphibians: Variation in sensitivity among species. Environmental Pollution 154, 291-297.

Sodhi, N.S., Bickford, D., Diesmos, A.C., Lee, T.M., Koh, L.P., Brook, B.W. et al. (2008). Measuring the meltdown: Drivers of global amphibian extinction and decline. PLOS ONE 3, e1636.

Stuart, S.N., Chanson, J.S., Cox, N.A., Young, B.E., Rodrigues, A.S.L., Fischman, D.L. et al. (2005). Status and trends of amphibian declines and extinctions worldwide. Science 306, 1783-1786.

Veronez, A.C. da S., Salla, R.V., Baroni, V.D., Barcarolli, I.F., Bianchini, A., dos Reis Martinez, C.B et al. (2016). Genetic and biochemical effects induced by iron ore, Fe and Mn exposure in tadpoles of the bullfrog Lithobates catesbeianus. Aquatic Toxicology 174, 101-108.

Walsh, P.T., Downie, J.R. \& Monaghan, P. (2008). Larval over-wintering: Plasticity in the timing of life-history events in the common frog. Journal of Zoology 276, 394-401.

Walsh, P.T., Downie, J.R. \& Monaghan, P. (2016). Factors affecting the overwintering of tadpoles in a temperate amphibian. Journal of Zoology 298, 183-190.

Wei, L., Ding, G., Guo, S., Tong, M., Chen, W., Flanders, J. et al. (2015). Toxic effects of three heavy metallic ions on Rana zhenhaiensis tadpoles. Asian Herpetological Research 6, 132-142.

Werner, E.E. \& Gilliam, J.F. (1984). The ontogenetic niche and species interactions in size-structured populations. Annual Review of Ecology and Systematics 15, 393-425.

White, K.J., Mayes, W.M. \& Petrovan, S.O. (2017).
Identifying pathways of exposure to highway pollutants in great crested newt (Triturus cristatus) road mitigation tunnels. Water and Environment Journal 31, 310-316.

Woods Ballard, B., Wilson, S., Udale-Clarke, H., Illman, S., Scott, T., Ashley, R. \& Kellagher, R. (2015). The SUDS Manual. CIRIA, London. http://www.scotsnet.org.uk/documents/NRDG/ CIRIA-report-C753-the-SuDS-manual-v6.pdf

Wu, C.S., Gomez-Mestre, I. \& Kam, Y.C. (2012). Irreversibility of a bad start: Early exposure to osmotic limits growth and adaptive developmental plasticity. Physiological Ecology 169, 15-22.

Zhang, X., Wu, Y. \& Gu, B. (2015). Urban rivers as hotspots of regional nitrogen pollution. Environmental Pollution 205, 139-144. 


\section{SUPPLEMENTARY INFORMATION}

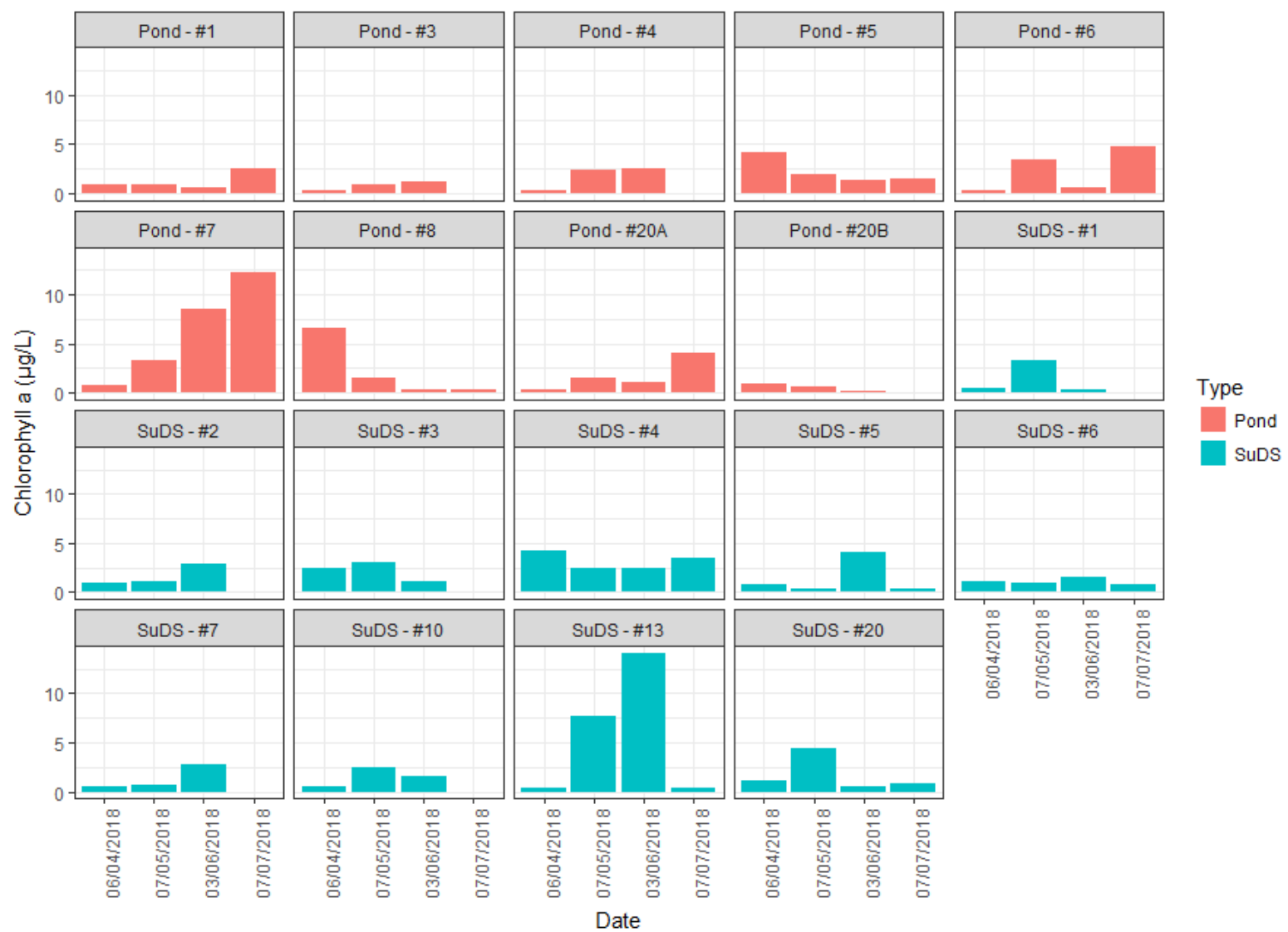

Fig. 6. Chlorophyll $a$ concentrations in natural ponds (red bars) and SuDS (blue bars) surveyed at East Kilbride, Scotland over the four sampling periods during 2018. Data from eight sites are not shown for July, due to the water body drying out.
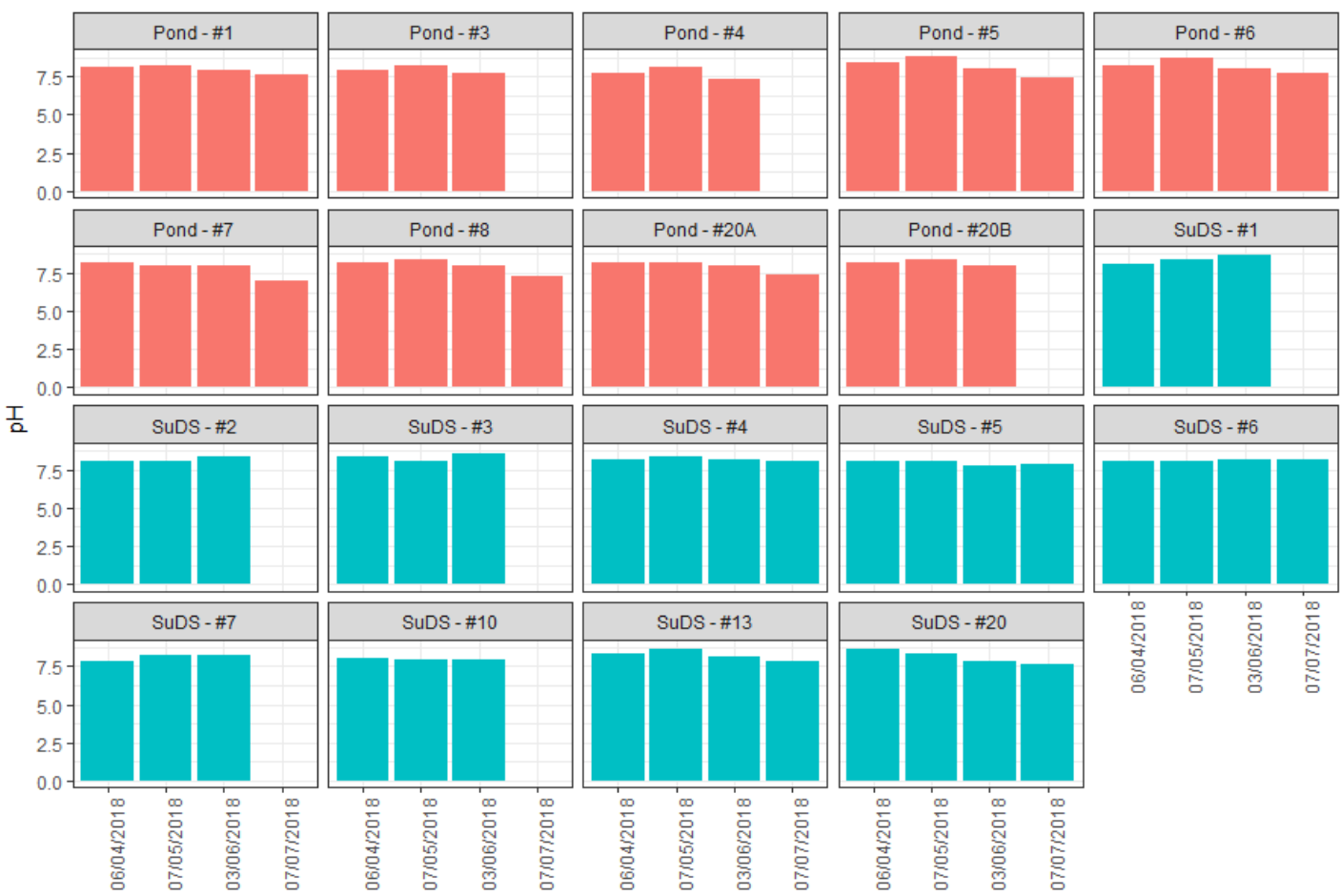

Type

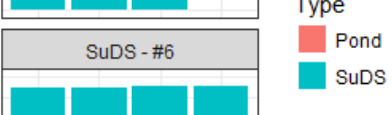

periods during 2018. Data from eight sites are not shown for July, due to the water body drying out. 


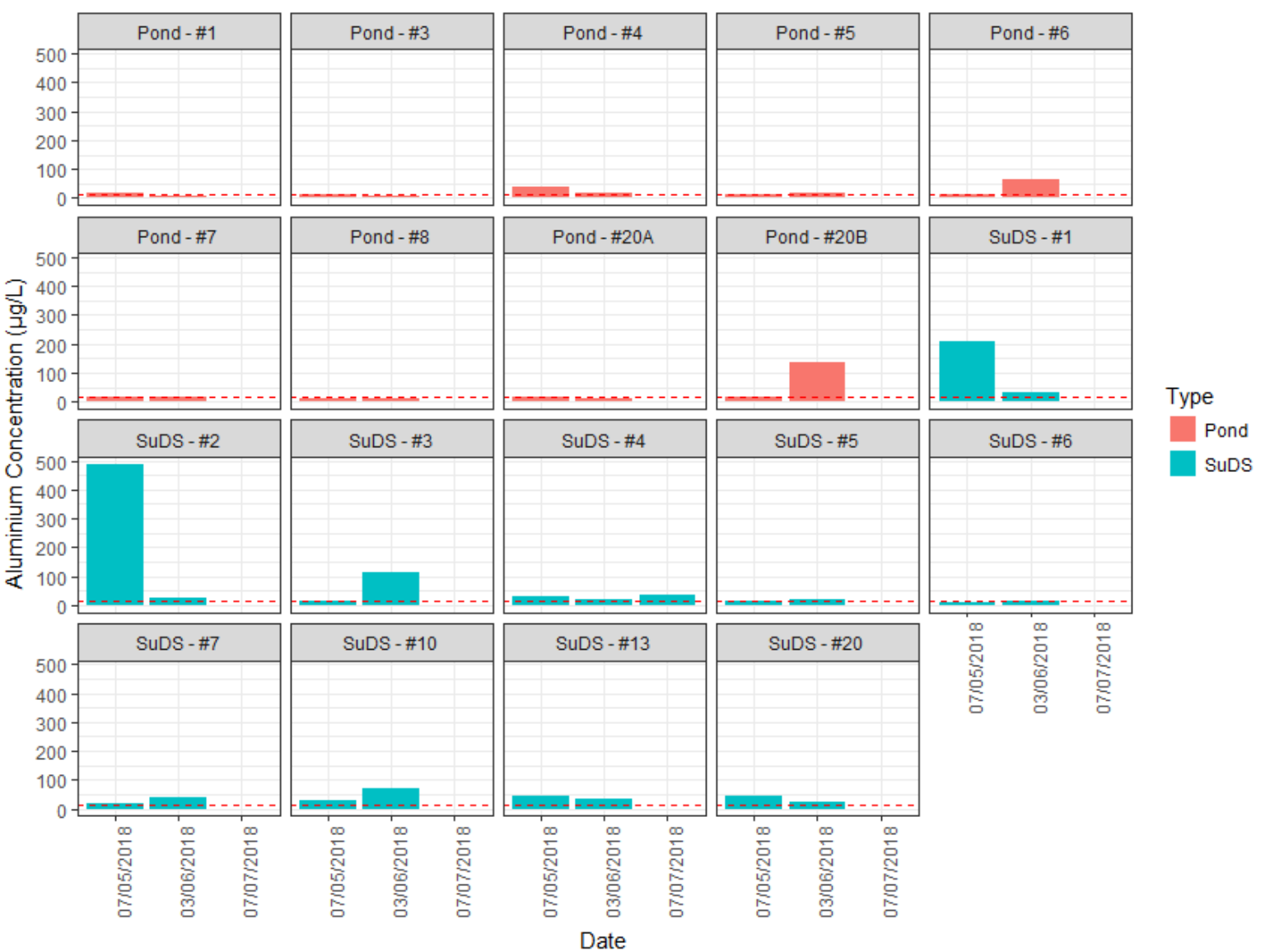

Fig. 8. Aluminium concentrations in natural ponds (red bars) and SuDS (blue bars) surveyed at East Kilbride, Scotland over the three sampling periods during 2018.

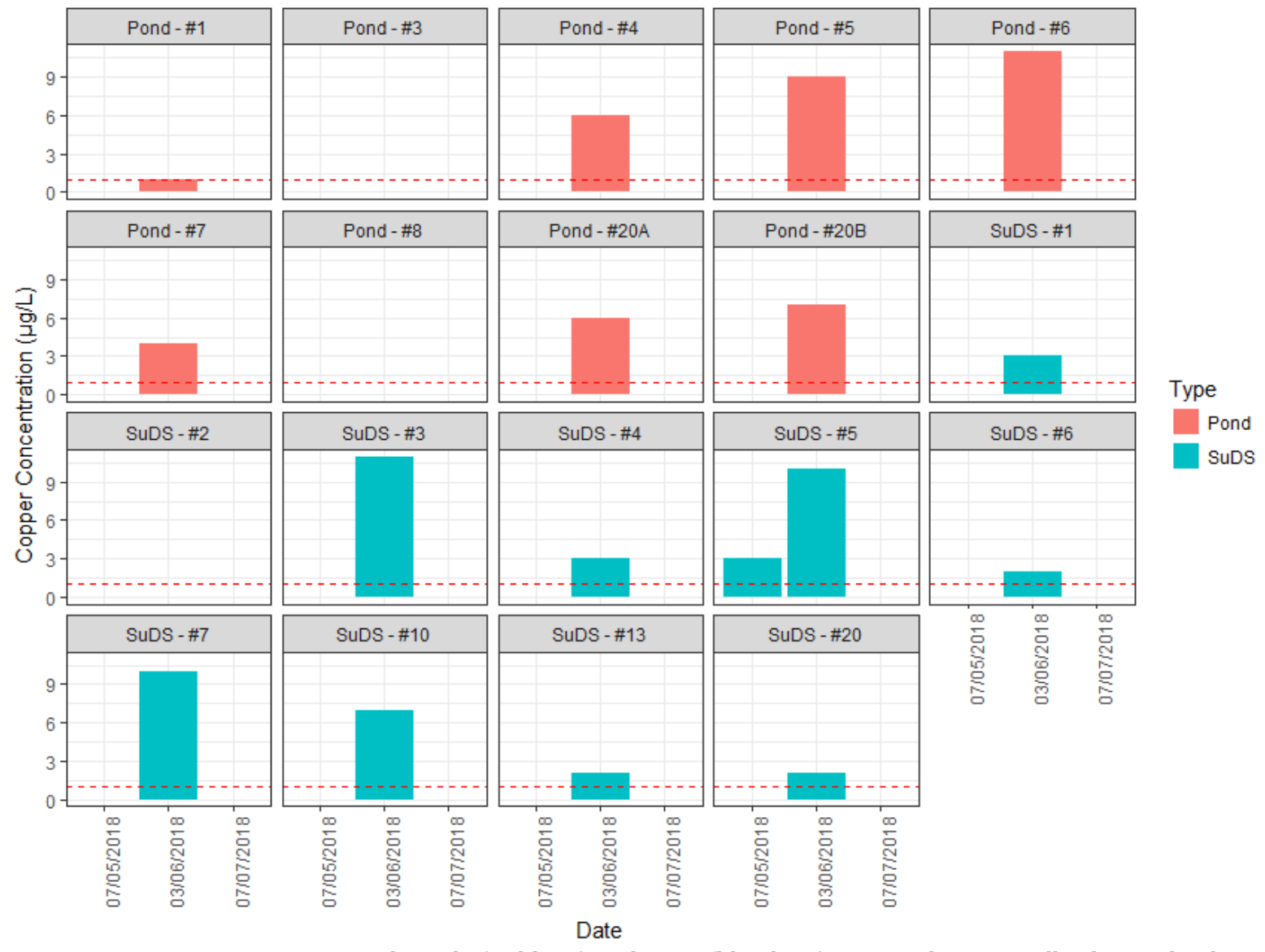

Fig. 9. Copper concentrations in natural ponds (red bars) and SuDS (blue bars) surveyed at East Kilbride, Scotland over the three sampling periods during 2018. 

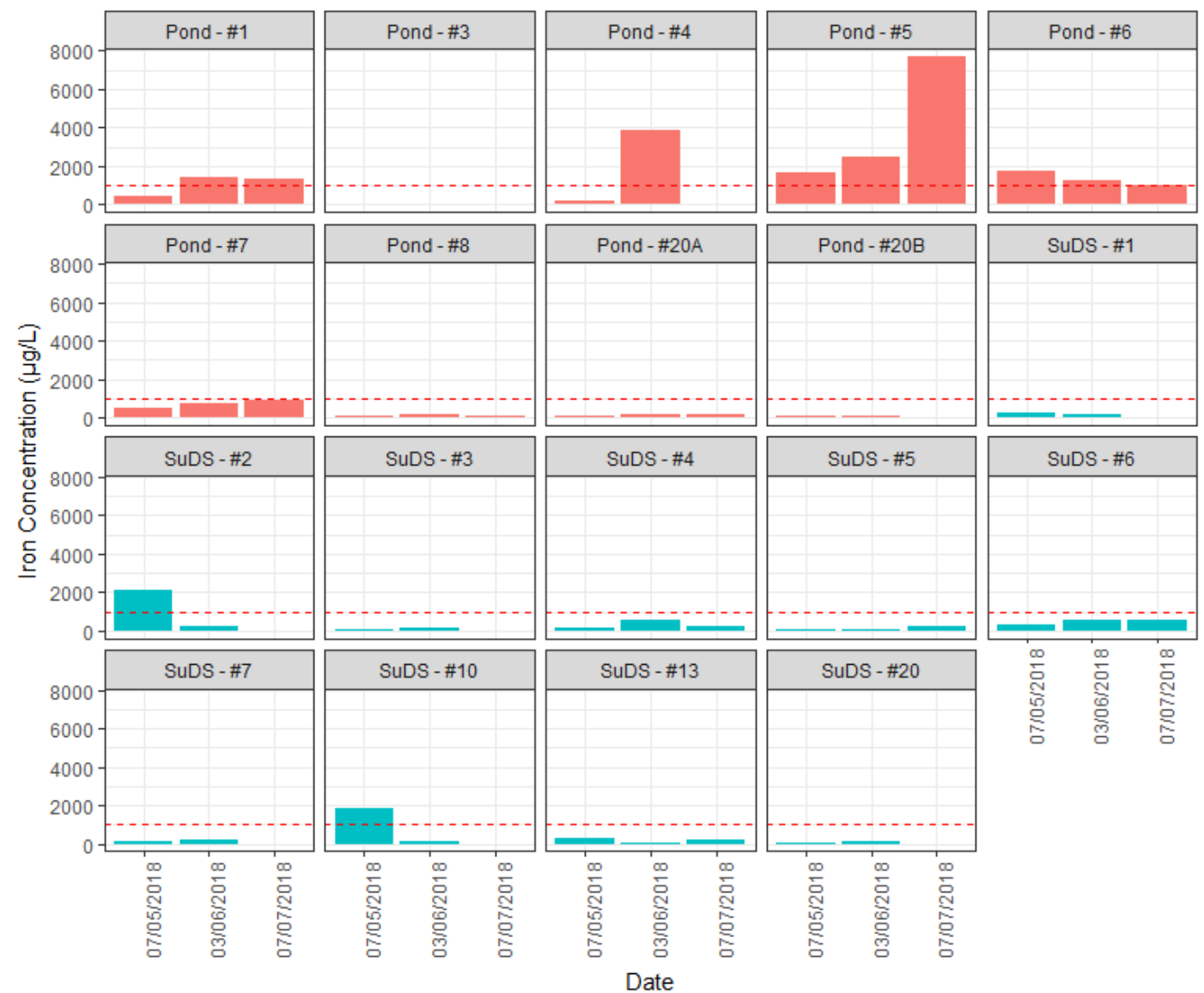

Type

Pond

SuDS

Fig. 10. Iron concentrations in natural ponds (red bars) and SuDS (blue bars) surveyed at East Kilbride, Scotland over the three sampling periods during 2018.
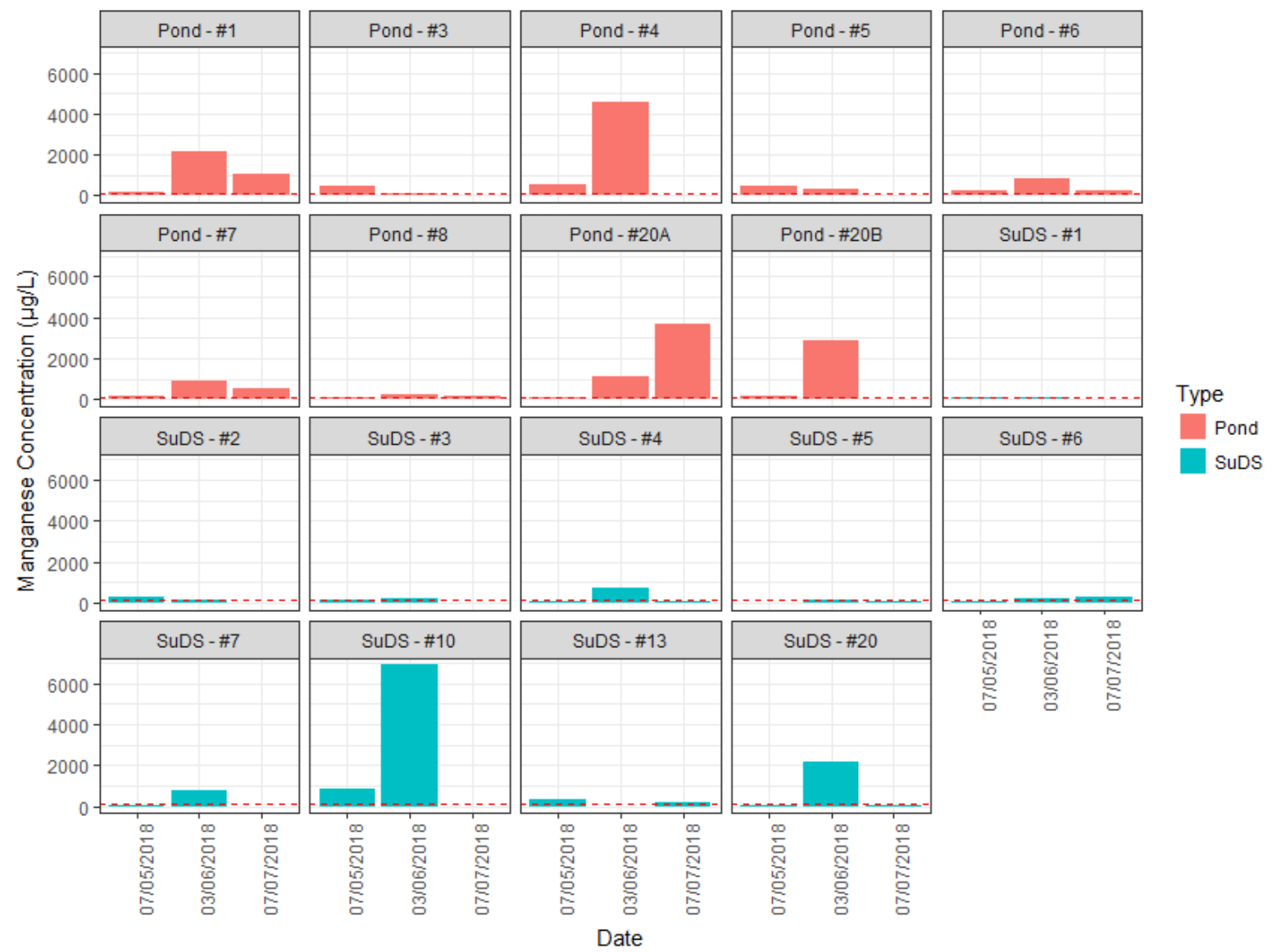

Fig. 11. Manganese concentrations in natural ponds (red bars) and SuDS (blue bars) surveyed at East Kilbride, Scotland over the three sampling periods during 2018. 


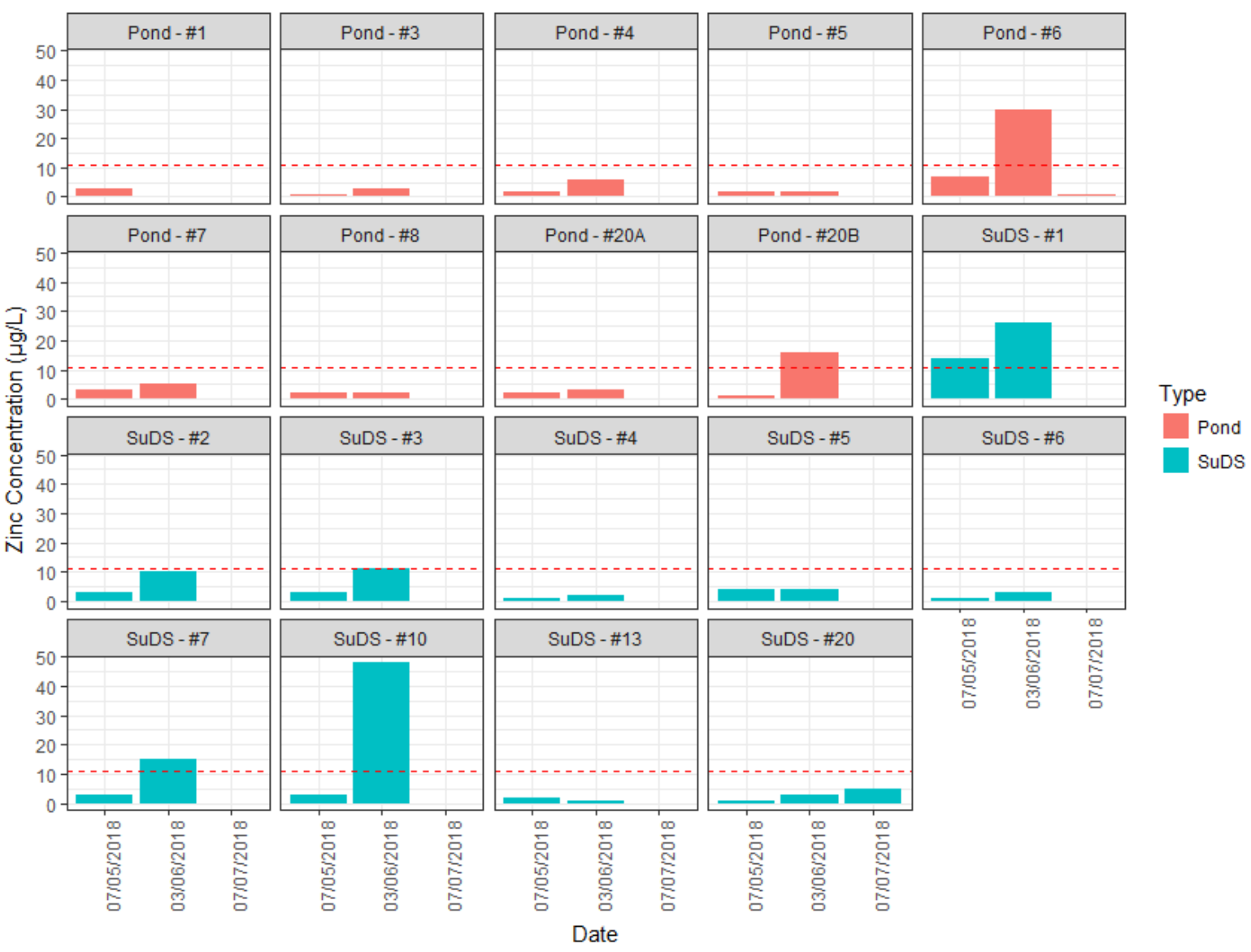

Fig. 12. Zinc concentrations in natural ponds (red bars) and SuDS (blue bars) surveyed at East Kilbride, Scotland over the three sampling periods during 2018. 